\title{
Potential of snake fruit (Salacca zalacca (Gaerth.) Voss) for the development of a beverage through fermentation with the Kombucha consortium
}

\author{
Elok Zubaidah $^{\mathrm{a}, *}$, Firka Julian Dewantari ${ }^{\mathrm{a}}$, Fitria Rizki Novitasari ${ }^{\mathrm{a}}$, Ignatius Srianta ${ }^{\mathrm{b}}$, \\ Philippe J. Blanc ${ }^{\mathrm{c}}$ \\ a Department of Food Science and Technology, Faculty of Agricultural Technology, Brawijaya University, Jalan Veteran, Malang 65145, Indonesia \\ ${ }^{\mathrm{b}}$ Department of Food Technology, Faculty of Agricultural Technology, Widya Mandala Catholic University Surabaya, Jalan Dinoyo 42-44, Surabaya 60265, Indonesia \\ ${ }^{\mathrm{c}}$ Université de Toulouse, INSA, LISBP, CNRS, UMR5504, INRA, UMR792, Ingénierie des Systèmes Biologiques et des Procédés, 135 Avenue de Rangueil, F-31077 \\ Toulouse, France
}

\section{A R T I C L E I N F O}

\section{Keywords:}

Snake fruit

Kombucha consortium

Antioxidant

Antibacterial

Bioactive compounds

Sensory properties

\begin{abstract}
A B S T R A C T
Sugared snake fruit juices were fermented for 14 days with the Kombucha consortium containing yeasts and acetic acid bacteria. Five Indonesian cultivars (Salak Doyong, Salak Madu, Salak Pondoh, Salak Segaran and Salak Suwaru) of the fruit were studied. The physicochemical and sensory properties of the fermented products revealed the snake fruit Kombucha from the Salak Suwaru cultivar as the most acceptable with color indices $L^{*}$ and b* respectively 30.5 and 13.2; total sugar, 7.54\%; total soluble solids, $11.3 \%$; total acidity, 1.65\%; $\mathrm{pH}, 3.15$; and sensory scores (out of 5) of 3.90 for color, 3.70 for taste and 3.80 for aroma. The fermentation enhanced antioxidant activity of the snake fruit Kombucha, as assessed by 2,2-diphenyl-1-picrylhydrazyl (DPPH) radical scavenging activity, and consistent with increases in phenolics, tannins and flavonoids. Acetic acid was the major organic acid of the fermented product that showed an enhanced antibacterial activity by inhibiting Gram-positive (Staphylococcus aureus) and Gram-negative (Escherichia coli) bacteria. Snake fruits can be used to develop functional food beverages and foods through the Kombucha fermentation.
\end{abstract}

\section{Introduction}

Snake fruit (Salacca zalacca (Gaerth.) Voss) is a tropical fruit widely found in South East Asia. It is known by various names such as Salak (Indonesia, Malaysia and Philippines), Rakam (Thailand), Sa Laka and She Pi Guo Zong (China), Schlagenfrucht and Zalak (Germany), Sarakka Yashi (Japan), Salaca (Span) andYingan (Myanmar) (Mohd Zaini et al., 2013). It has a white firm pulp with a sweet, slight acidic and astringent taste. Snake fruit is a good source of vitamins, minerals, dietary fiber, and bioactive compounds with antioxidant activities (Aralas et al., 2009; Suica-Bunghez et al., 2016). There are many snake fruit cultivars or genotypes worldwide, and each cultivar has unique physical, chemical and sensory characteristics. The ripe fruit is mostly eaten fresh, but it can also be processed into canned fruits, juices, dried fruits, pickles, syrups, and fermented products. Some studies revealed the suitability of sugared snake fruit juice for wine and vinegar fermentations, as it is a good medium for relevant microorganisms (Gunam et al., 2009; Zubaidah et al., 2017). This favourable fermentability property of the sugared snake fruit can be explored for other fermented products with functional properties.
Kombucha (tea fungus) is a refreshing health-promoting beverage of sugared tea infusion fermented by a symbiotic consortium of yeast species and acetic acid bacteria. Various yeasts (e.g. Pichia, Candida, Zygosaccharomyces, Brettanomyces, and Saccharomyces species) and Acetobacter xylinum have been identified in Kombucha fermentation (Jayabalan et al., 2014). The beverage possesses functional properties such as antimicrobial, antioxidant, anticancer, and antidiabetic, and is beneficial in treating gastric ulcer (Jayabalan et al., 2011; Aloulou et al., 2012; Bhattacharya et al., 2013; Banerjee et al., 2011; Chakravorty et al., 2016). Specifically, Kombucha is reported (Sreeramalu et al., 2000; Jayabalan et al., 2014) to inhibit a broad spectrum of Gram-positive (e.g. Staphylococcus aureus and Bacillus cereus) and Gram-negative bacteria (e.g. Escherichia coli and Pseudomonas aeruginosa). Moreover, total phenolic compounds and radical scavenging activities of Kombucha increase with fermentation time (Jayabalan et al., 2014). In view of the functional properties of Kombucha, substrates other than tea had been studied, including Jerusalem artichoke, echinacea, mentha, eucalyptus, sour cherry, grape, orange, and blackcurrant (Yavari et al., 2010, 2011; Jayabalan et al., 2014; Gamboa-Gómez et al., 2016; Lobanova et al., 2016; Ayed et al., 2017).

\footnotetext{
* Corresponding author.

E-mail addresses: elzoeba@yahoo.com, elok@ub.ac.id (E. Zubaidah).
} 
However, we are unaware of the fermentation of snake fruit juices with the Kombucha consortium, and in view of the global availability of snake fruits, a study along these lines would provide another product to health-conscious consumers particularly in areas where snake fruits are abundant. Therefore, using different cultivars of snake fruit to understand cultivar effects, the objectives of this research were to:

(a) Investigate fermentation of snake fruit with the Kombucha consortium.

(b) Evaluate physicochemical and sensory properties of the fermented products.

(c) Assess antioxidant and antibacterial activities of the most promising cultivar, with its bioactive compounds.

\section{Materials and methods}

\subsection{Materials}

Snake fruits of commercial maturity were obtained from plantations in Malang, Jombang and Kediri, East Java, Indonesia, and were of cultivars Salak Doyong, Salak Madu, Salak Pondoh, Salak Segaran, and Salak Suwaru. Commercial Kombucha starter was purchased from a local distributor, while cane sugar was bought from a local supermarket.

\subsection{Snake fruit juice preparation and Kombucha fermentation}

The snake fruits were peeled, washed, and cut into small sizes, from which $400 \mathrm{~g}$ was mixed (1:1, w/w) with water, juiced (blended) and filtered (cheese cloth). The snake fruit juices were sweetened (1:10, w/ v) with the cane sugar, pasterurized (Waterbath Memmert, Germany) at $65{ }^{\circ} \mathrm{C}$ for $30 \mathrm{~min}$ and cooled to room temperature before storing in a sterile jar and refrigerating until used. The juices were sweetened or sugared to provide additional sugars and facilitate fermentation as reported elsewhere (Sreeramalu et al., 2000; Jayabalan et al., 2014). The sugared juices were inoculated $(1: 10 \mathrm{w} / \mathrm{w})$ with the Kombucha starter and incubated for 14 days at room temperature. Samples of the fermenting broth were taken at days 0,7 and 14 for analysis.

\subsection{Media and chemicals}

Culture media, nutrient agar (CM0003 Oxoid $\left.^{\mathrm{TM}}\right)$ and potato dextrose agar (CM0139 Oxoid $^{\mathrm{TM}}$ ) were products of Thermo Fischer Scientific, USA. Sodium hydroxide (Merck 106462, Germany), oxalic acid (Merck 100495, Germany), anthrone reagent (Merck 101468, Germany), sulphuric acid (Merck 100731, Germany), glucose (Merck 108337, Germany), gallic acid (Sigma-Aldrich, Germany), Folin-Ciocalteau phenol reagent (Sigma F9252, Sigma-Aldrich, Germany), tannic acid (Sigma-Aldrich, Germany), quercetin (Sigma-Aldrich, Germany), sodium carbonate (Merck 1063950500, Germany), and 2,2-diphenyl-1picrylhydrazyl (DPPH) (Sigma-Aldrich, Germany) used, were products of the indicated suppliers, and were of an analytical grade, as well as other minor reagents.

\subsection{Physicochemical analysis}

Color was measured by a color reader (Konica Minolta CR-10, Japan) and pH by a pH meter (Hanna, Thermo Fischer Scientific, USA). Total sugar was determined by the anthrone method (Islam et al., 2013) with modifications, whereby $1 \mathrm{~mL}$ of the fermented or non-fermented juices was transfered to a test tube and mixed with $5 \mathrm{~mL}$ of the anthrone reagent $\left(0.05 \mathrm{~g}\right.$ anthrone in $50 \mathrm{~mL}$ of concentrated $\left.\mathrm{H}_{2} \mathrm{SO}_{4}\right)$. The test tube were held at $100{ }^{\circ} \mathrm{C}$ for $12 \mathrm{~min}$ and cooled before measuring the absorbance at $630 \mathrm{~nm}$ in a spectrophotometer (Spectro 20D Plus, Labomed, USA) with a glucose solution as the standard. Total acidity was measured according to Ranggana (1977), whereby $10 \mathrm{~mL}$ of the fermented or non-fermented juices was mixed with $100 \mathrm{~mL}$ of distilled water and some drops of $1 \%$ phenolphthalein indicator, and then titrated with $0.1 \mathrm{M} \mathrm{NaOH}$.Total soluble solids of the samples were measured by refractometry (Atago handheld refractometer $\mathrm{N}-1 \mathrm{E}$, Japan). One drop of sample was placed on the prism, closed the daylight plate over the sample, then read through the focusable cushionedrubber eyepiece.

\subsection{Microbiological analysis}

Yeast and bacteria counts of the Kombucha samples were done using the standard plate count procedure according to BAM-FDA protocol (Maturin and Peeler, 2001) that involved mixing $1 \mathrm{~mL}$ of the samples with $9 \mathrm{~mL}$ of sterile $0.1 \%$ peptone water $\left(10^{-1}\right.$ dilution). Aliquots of the mixture and subsequent dilutions were further diluted with the peptone water to have serial decimal dilutions from $10^{-2}$ to $10^{-8}$. One milliliter of each dilution was transfered into duplicated petri dishes, into which $15 \mathrm{~mL}$ of sterile nutrient agar $\left(50{ }^{\circ} \mathrm{C}\right)$ containing cycloheximide $(4 \mathrm{~g} / \mathrm{L})$ to prevent yeast growths was poured, mixed immediately and left to solidify before incubation at $37^{\circ} \mathrm{C}$ for $24 \mathrm{~h}$., after which the growths were counted. For yeast counts, the same procedure was followed without the addition of cycloheximide, but with the potato dextrose agar as the medium and the incubation was at $30{ }^{\circ} \mathrm{C}$ for $48 \mathrm{~h}$.

\subsection{Antioxidant and antibacterial activities}

Antioxidant activity was measured in vitro by using the DPPH radical scavenging activity method (Hatano et al., 1988), whereby $1 \mathrm{~mL}$ of $0.2 \mathrm{mM}$ DPPH solution was mixed with $2 \mathrm{~mL}$ of the snake fruit Kombucha. The mixture was incubated in a dark room for $30 \mathrm{~min}$ and the absorbance was measured at $517 \mathrm{~nm}$ with the control being the sample blank. Changes in the absorbance were measured, and antioxidant activity was expressed as \% DPPH radical scavenging ability.

Antibacterial activity assay against pathogenic bacteria Staphylococcus aureus and Escherichia coli was conducted by using the agar diffusion technique of Wolf and Gibbon (1996). One milliliter of the indicator bacteria culture with $10^{8}$ colony forming units (cfu) per $\mathrm{mL}$ was transfered to a sterile petri dish, into which $10 \mathrm{~mL}$ of sterile nutrient agar was poured, and upon solidification, six $8 \mathrm{~mm}$-diameter wells were made by a sterile perforator. An appropriate volume $(100 \mu \mathrm{L})$ of sterile snake fruit Kombucha was transferred into the well and incubated at $37^{\circ} \mathrm{C}$ for $24 \mathrm{~h}$. The diameter of the inhibition zone was measured with a micrometer.

\subsection{Bioactive compounds analysis}

Total phenolic content was determined with the Folin-Ciocalteu reagent (Yang et al., 2007) using gallic acid as the standard. One milliliter of the methanolic extract of the fermented or non-fermented juices was placed into a test tube and vortexed (Nissin mixer N-20 M, USA) for $15 \mathrm{~s}$ with $1.5 \mathrm{~mL}$ of the Folin-Ciocalteau reagent, and allowed to stand at room temperature for $5 \mathrm{~min}$, before adding $1.5 \mathrm{~mL}$ of $0.57 \mathrm{M}$ $\mathrm{Na}_{2} \mathrm{CO}_{3}$ and incubated for $90 \mathrm{~min}$ at room temperature. Absorbance was measured at $750 \mathrm{~nm}$ using the spectrophotometer, with the same mixture except the sample extract was replaced by methanol as the blank. Total phenolic content was expressed as mg GAE (Gallic Acid Equivalent)/L.

Tannin content was determined with the Vanilin- $\mathrm{HCl}$ method as described by Price et al. (1978) with minor modifications, whereby $1 \mathrm{~mL}$ of the test juice was mixed with $5 \mathrm{~mL}$ of Vanillin/ $\mathrm{HCl}$ mixture in a test tube and held for $20 \mathrm{~min}$ at room temperature. The formed color was determined at $500 \mathrm{~nm}$ wavelength. The tannic acid was used as the standard, and tannin content was expressed as mg TAE (Tannic Acid Equivalent)/L.

Total flavonoids were estimated according to the method of Nabavi 
et al. (2008), and this involved adding $0.4 \mathrm{~mL}$ of the test juice to $4 \mathrm{~mL}$ of distilled water, before $0.3 \mathrm{~mL}$ of $0.72 \mathrm{M} \mathrm{NaNO}_{2}$ was added. After $5 \mathrm{~min}, 0.3 \mathrm{~mL}$ of $0.75 \mathrm{M} \mathrm{AlCl}_{3}$ was added, after $6 \mathrm{~min}, 2 \mathrm{~mL}$ of $1 \mathrm{M}$ $\mathrm{NaOH}$ was added and the total volume was measured at $510 \mathrm{~nm}$ against a reagent blank. Quercetin was used as the standard, and total flavonoid content was expressed as mg QE (Quercetin Equivalent)/L.

Organic acid composition of the Kombucha was analysed by using HPLC (Jayabalan et al., 2007), and this involved centrifuging (Minispin Eppendorf, Germany) $2 \mathrm{~mL}$ of the test juice at 12,000 rpm ( $9677 \mathrm{~g}$ ) for $10 \mathrm{~min}$ and filtering through $0.45 \mu \mathrm{m}$ filter membrane. The filtrate was injected to a column (MethaCarb H Plus $300 \times 7.8 \mathrm{~mm}$, Agilent, USA) with a mobile phase of $0.005 \mathrm{M} \mathrm{H}_{2} \mathrm{SO}_{4}$ at a flow rate $0.6 \mathrm{~mL} / \mathrm{min}$. Separation was conducted at $70{ }^{\circ} \mathrm{C}$ with running time of $25 \mathrm{~min}$, and detection was with a UV detector at $215 \mathrm{~nm}$, while organic acids (acetic acid, citric acid, malic acid, lactic acid, formic acid, propionic acid and butiric acid) were the standards.

\subsection{Sensory evaluation}

Sensory evaluation of the snake fruit Kombucha was conducted by using hedonic method (Stone and Sidel, 2004). A 5-point scoring was used with 1 representing extremely dislike and 5 representing extremely like. Thirty untrained panelists participated in the sensory evaluation, and had no previous or present taste or smell disorders. Kombucha samples were labeled with three-digit codes and randomly presented to avoid bias of order of presentation. The panelists scored for color, aroma and taste of the 14-day fermented snake fruit Kombucha from the five cultivars. The study was in accordance with the Declaration of Helsinki (Anon, 2017).

\subsection{Statistical analysis}

All the analyses above were conducted at least in triplicate. Data were analysed with the Analysis of Variance (ANOVA), and further analysis was conducted with the Least Square Difference (LSD), and both were at a 5\% significant level (Granato et al., 2014). The Multiple Attribute Analysis was used to determine the most promising snake fruit cultivar Kombucha (Zeleny, 1982).

\section{Results and discussion}

\subsection{Physicochemical characteristics of the snake fruit juice and Kombucha}

Table 1 shows the chemical characteristics of the snake fruit juices from the five cultivars. It can be observed that there were no cultivar differences for $\mathrm{pH}$ and total acidity, but the Salak Suwaru cultivar had the highest sugar and phenolic contents (Table 1).

Visually, there was a pellicle on top of the fermented products, as reported by Sreeramulu et al. (2000) in common tea Kombucha, and this is thought to be a thin layer of cellulose produced by Acetobacter xylinum during the fermentation. The snake fruit Kombucha was brownish yellow with color indices $L^{*}$ and $b^{*}$ of about 31 and 13 respectively, and significantly ( $\mathrm{p}>0.05$ ) independent of the cultivars (Table 2). The brownish color resulted from enzymatic browning during the snake fruit processing, when inherent polyphenoloxidase (PPO) acted on the fruit's naturally occurring phenolic compounds. Mohd Zaini et al. (2013) found membrane-bound PPO to be 90 times more active than soluble PPO, but the activity can be, at least, halved upon treatments at $60{ }^{\circ} \mathrm{C}$ for $20 \mathrm{~min}$ or more. With the snake fruit juices, the pasteurization $\left(65^{\circ} \mathrm{C}\right.$ for $30 \mathrm{~min}$ ) would have substantially reduced the PPO, and a much lower activity would be expected during the fermentation, and the low $\mathrm{pH}$ (or high acidity) of the fermenting juices, due to organic acids produced by the Kombucha consortium, would have enhanced the PPO inactivation. Mohd Zaini et al. (2013) found out that $\mathrm{pH} 3$ fully inactivated snake fruit $\mathrm{PPO}$, and the $\mathrm{pH}$ of the snake fruit Kombucha ranged from 2.8 to 3.2 (Table 2).

The total sugar and soluble solids of the snake fruit Kombucha were not significantly $(\mathrm{p}>0.05)$ affected by the cultivars, and were generally about $7 \%$ and $10 \%$ respectively (Table 2 ). The total sugar content was higher than those in tea Kombucha reported by previous researchers such as Blanc (1996), Sievers et al. (1995), and Sreeramulu et al. (2000). This result may be due to a higher initial total sugar of the snake fruit juices in the present study, and possible differences in the concentrations and microbial profiles of the Kombucha consortia used. Sucrose facilitates Kombucha fermentations better than glucose and fructose (Greenwalt et al., 2000). Yeasts in the Kombucha consortium breakdown sucrose into glucose and fructose, and the former is more utilized and metabolized to produce ethanol and carbon dioxide.

There were significant $(\mathrm{p}<0.05)$ cultivar differences in the total acidity and $\mathrm{pH}$ of the snake fruit Kombucha, with the Salak Suwaru Kombucha having the highest total acidity (Table 2), despite the corresponding juice having nominally the lowest total acidity (Table 1). This possibly indicated that the highest acid production occurred in the Salak Suwaru product, and it might be connected with the Salak Suwaru juice nominally having the highest total sugar prior (Table 1 ) to fermentation. This is consistent with Blanc (1996), who directly related metabolites present in Kombucha to the amount of sugar. However, comparing the sugar levels (natural and added) in the fermented (Table 2) and non-fermented (Table 1) products, the Kombucha fermentation led to about the same (45-47\%) metabolized sugar percentages in the cultivars. Hence, although its highest total acidity ought to be accompanied by lowest $\mathrm{pH}$ and sugar, the highest $\mathrm{pH}$ (significant) and total sugar (nominal) measured with the Salak Suwaru Kombucha could indicate the cultivar had inherent high acid production properties that could make the cultivar a strong potential for developing appropriate Kombucha products.

\subsubsection{Microbial and chemical changes during the Kombucha fermentation}

As expected and irrespective of the snake fruit cultivars, there were changes to the microbial and chemical characteristics of the juices during the Kombucha fermentation (Fig. 1), as the yeasts and bacteria metabolized the fermentable constituents of the juices. The yeast and bacteria growth patterns were similar among the snake fruit cultivars, with the counts increasing during the first seven days of fermentation, before decreasing, which had been associated with acid shocks on the microorganisms. This trend agrees with the studies of Sreeramulu et al. (2000) on the Kombucha fermentation of sugared tea infusion. We observed that the microbial growths led to decreases of the total sugar,

Table 1

Snake fruit juice characteristics."

\begin{tabular}{|c|c|c|c|c|}
\hline Cultivar & Total acidity (\%) & $\mathrm{pH}$ & Total sugar (\%) & Phenolic content(mg GAE/L) \\
\hline Salak Doyong & $0.43 \pm 0.03^{\mathrm{a}}$ & $4.19 \pm 0.11^{\mathrm{a}}$ & $3.57 \pm 0.09^{\mathrm{a}}$ & $250 \pm 7.05^{\mathrm{a}}$ \\
\hline Salak Madu & $0.33 \pm 0.06^{\mathrm{a}}$ & $4.38 \pm 0.07^{\mathrm{a}}$ & $3.68 \pm 0.07^{\mathrm{a}}$ & $178 \pm 5.07^{\mathrm{a}}$ \\
\hline Salak Pondoh & $0.35 \pm 0.05^{\mathrm{a}}$ & $4.05 \pm 0.08^{a}$ & $3.64 \pm 0.12^{\mathrm{a}}$ & $229 \pm 9.01^{\mathrm{a}}$ \\
\hline Salak Segaran & $0.52 \pm 0.07^{\mathrm{a}}$ & $4.13 \pm 0.07^{\mathrm{a}}$ & $3.41 \pm 0.11^{\mathrm{a}}$ & $202 \pm 5.05^{\mathrm{bc}}$ \\
\hline Salak Suwaru & $0.31 \pm 0.04^{\mathrm{a}}$ & $4.42 \pm 0.13^{\mathrm{a}}$ & $4.11 \pm 0.08^{b}$ & $264 \pm 8.05^{c}$ \\
\hline
\end{tabular}

* Values are means \pm standard deviations, and values in a column with the same letters are not significantly (p $>0.05)$ different. This applies to all tables, where they appear. 
Table 2

Physicochemical properties of the snake fruit Kombucha.

\begin{tabular}{|c|c|c|c|c|c|c|}
\hline \multirow[t]{2}{*}{ Cultivar } & \multicolumn{2}{|l|}{ Color } & \multirow[t]{2}{*}{ Total sugar (\%) } & \multirow[t]{2}{*}{ Total soluble solid (\%) } & \multirow[t]{2}{*}{ Total Acidity (\%) } & \multirow[t]{2}{*}{$\mathrm{pH}$} \\
\hline & $L^{*}$ & $b^{*}$ & & & & \\
\hline Salak Doyong & $30.9 \pm 0.77^{\mathrm{a}}$ & $13.7 \pm 0.22^{\mathrm{a}}$ & $7.21 \pm 0.17^{\mathrm{a}}$ & $10.6 \pm 0.77^{\mathrm{a}}$ & $1.32 \pm 0.04^{\mathrm{c}}$ & $2.76 \pm 0.07^{\mathrm{a}}$ \\
\hline Salak Madu & $31.6 \pm 0.53^{\mathrm{a}}$ & $13.8 \pm 0.50^{\mathrm{a}}$ & $7.19 \pm 0.35^{\mathrm{a}}$ & $10.9 \pm 0.60^{\mathrm{a}}$ & $0.92 \pm 0.03^{\mathrm{a}}$ & $2.95 \pm 0.14^{\mathrm{ab}}$ \\
\hline Salak Pondoh & $31.3 \pm 0.67^{\mathrm{a}}$ & $13.3 \pm 0.58^{\mathrm{a}}$ & $7.44 \pm 0.41^{\mathrm{a}}$ & $10.8 \pm 0.25^{\mathrm{a}}$ & $1.23 \pm 0.04^{\mathrm{b}}$ & $2.85 \pm 0.11^{\mathrm{ab}}$ \\
\hline Salak Segaran & $30.5 \pm 0.93^{\mathrm{a}}$ & $13.7 \pm 0.49^{\mathrm{a}}$ & $7.34 \pm 0.12^{\mathrm{a}}$ & $10.5 \pm 0.61^{\mathrm{a}}$ & $1.44 \pm 0.05^{\mathrm{d}}$ & $2.82 \pm 0.06^{\mathrm{bc}}$ \\
\hline Salak Suwaru & $30.8 \pm 0.30^{\mathrm{a}}$ & $13.2 \pm 0.73^{\mathrm{a}}$ & $7.54 \pm 0.46^{\mathrm{a}}$ & $11.3 \pm 0.76^{\mathrm{a}}$ & $1.65 \pm 0.06^{\mathrm{e}}$ & $3.15 \pm 0.10^{\mathrm{c}}$ \\
\hline
\end{tabular}

with concomitant increases in the total acidity, as the yeasts in the Kombucha consortium symbiotically hydrolyzed sucrose to glucose and fructose to produce ethanol, which the acetic acid bacteria subsequent transformed to acetic and other organic acids. Consequently, the total acidity increased and the $\mathrm{pH}$ reduced, as widely reported for fermentations (Jayabalan et al., 2010; Velićanski et al., 2014; Gamboa-Gómez et al., 2016; Chakravorty et al., 2016), but there are secondary effects of fermentation that manifest in changes in or enhancement of sensory properties.

A

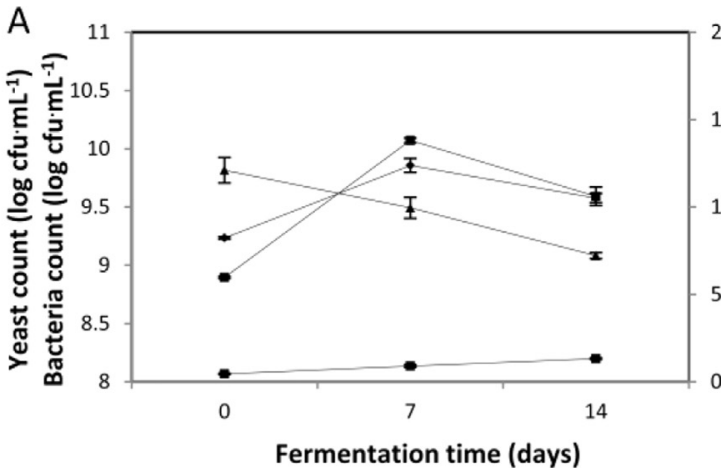

C

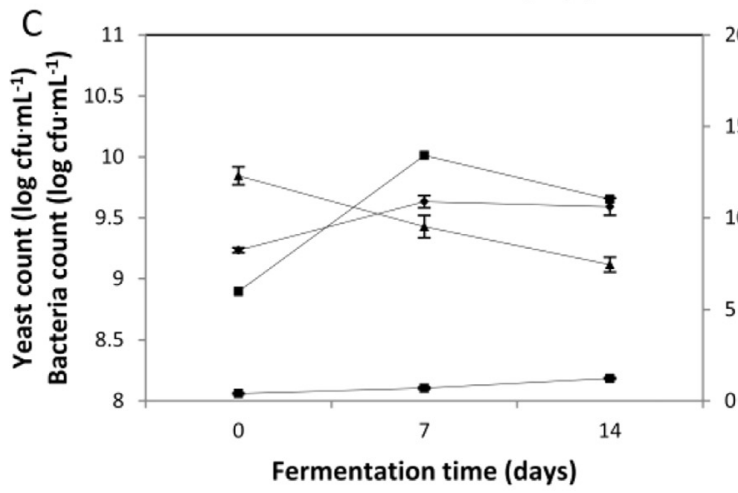

Table 3

Preference scores of the snake fruit Kombucha.

\begin{tabular}{llll}
\hline Cultivar & Color & Taste & Aroma \\
\hline Salak Doyong & $3.93 \pm 0.60^{\mathrm{a}}$ & $3.60 \pm 1.50^{\mathrm{ab}}$ & $3.53 \pm 1.02^{\mathrm{b}}$ \\
Salak Madu & $3.53 \pm 0.51^{\mathrm{a}}$ & $4.13 \pm 1.57^{\mathrm{c}}$ & $3.83 \pm 0.91^{\mathrm{b}}$ \\
Salak Pondoh & $3.50 \pm 0.80^{\mathrm{a}}$ & $4.07 \pm 1.48^{\mathrm{bc}}$ & $3.70 \pm 0.65^{\mathrm{b}}$ \\
Salak Segaran & $4.17 \pm 1.01^{\mathrm{a}}$ & $3.20 \pm 1.13^{\mathrm{a}}$ & $3.07 \pm 0.71^{\mathrm{a}}$ \\
Salak Suwaru & $3.90 \pm 1.12^{\mathrm{a}}$ & $3.70 \pm 1.29^{\mathrm{abc}}$ & $3.80 \pm 0.83^{\mathrm{b}}$
\end{tabular}

$*$ Extremely like $=5$ and Extremely dislike $=1$.

B
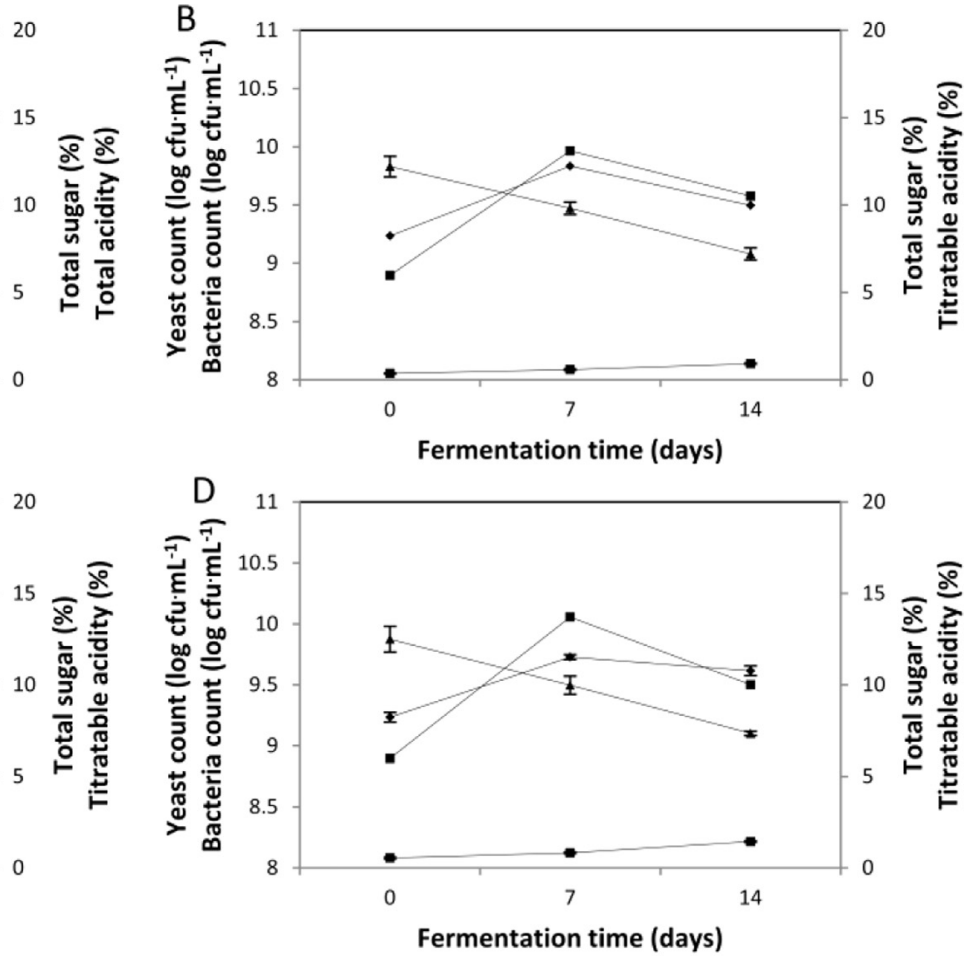

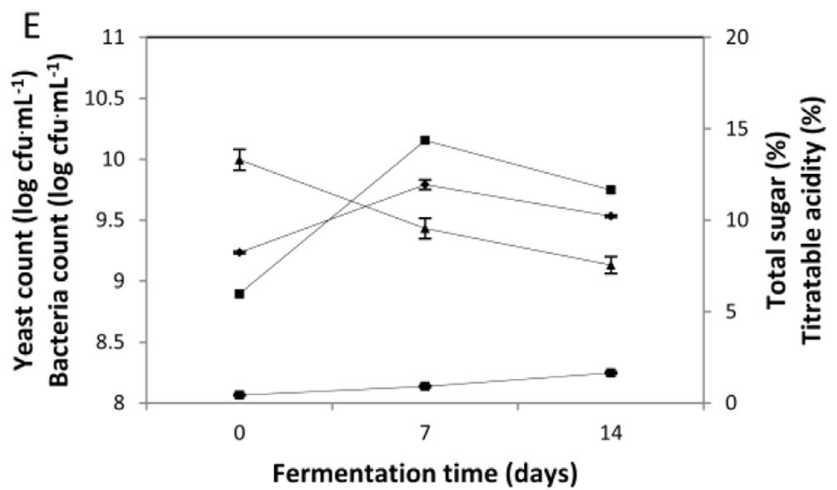

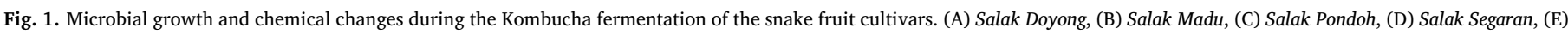
Salak Suwaru. : Yeast count, $\mathbf{\square}$ : Bacteria count, $\mathbf{\Delta}$ : Total sugar, x: Total acidity. 
Table 4

Bioactivities and bioactive compounds of the Salak Suwarusnake fruit kombucha.

\begin{tabular}{lll}
\hline $\begin{array}{l}\text { Bioactivities/Bioactive } \\
\text { compounds }\end{array}$ & Fermentation day $\mathbf{0}$ & Fermentation day 14 \\
\hline $\begin{array}{l}\text { Antioxidant activity (\% DPPH } \\
\text { scavenging activity) }\end{array}$ & $10.17 \pm 0.56^{\mathrm{a}}$ & $18.03 \pm 0.36^{\mathrm{b}}$ \\
$\begin{array}{l}\text { Antibacterial activity against } \\
\quad \text { clear zone diameter, mm): }\end{array}$ & & \\
$\begin{array}{l}\text { Staphylococcus aureus } \\
\text { Escherichia coli }\end{array}$ & $8.43 \pm 0.27^{\mathrm{a}}$ & $21.60 \pm 0.53^{\mathrm{b}}$ \\
Total phenolic content (mg & $6.91 \pm 0.19^{\mathrm{a}}$ & $15.40 \pm 0.61^{\mathrm{b}}$ \\
$\quad$ GAE/L) & $275.00 \pm 4.51^{\mathrm{a}}$ & $623.00 \pm 9.71^{\mathrm{b}}$ \\
Tannin content (mg TAE/L) & $321.90 \pm 4.54^{\mathrm{a}}$ & $365.42 \pm 10.47^{\mathrm{b}}$ \\
Flavonoid content (mg QE/L) & $2307.14 \pm 102.50^{\mathrm{a}}$ & $3041.46 \pm 134.44^{\mathrm{b}}$ \\
Total acidity (\%) & $0.44 \pm 0.05^{\mathrm{a}}$ & $1.65 \pm 0.06^{\mathrm{b}}$ \\
\hline
\end{tabular}

\subsubsection{Sensory evaluation of the snake fruit Kombucha}

Table 3 shows the sensory evaluation results of the snake fruit Kombucha, indicating that the panelists generally liked the products in all the assessed parameters. Preference scores for the color were not significantly different among the cultivars, in accordance with the instrumental results shown in Table 2. However, the preference scores for taste and aroma showed significant $(\mathrm{p}<0.05)$ differences among the cultivars, as inherent properties of the cultivars manifested, with the Salak Segaran Kombucha being the least preferred based on the two attributes.

\subsubsection{Bioactivities and bioactive compounds of the Salak Suwaru snake fruit Kombucha}

The Multiple Attribute Analysis was applied to choose the most promising cultivar by determining the ideal value on each parameter of the Kombucha snake fruit characteristics. The best treatment selection result shows that the Salak Suwaru Kombucha has the highest value compared to the other cultivars. Further studies were, therefore, conducted on the Salak Suwaru Kombucha to fully understand its potential for the health-promoting beverage, and Table 4 shows the antioxidant and antibacterial activities of this snake fruit Kombucha.

The in vitro DPPH scavenging ability of the Salak Suwaru Kombucha slightly increased with fermentation to about $80 \%$, a result that compares with tea Kombucha (Chakravorty et al., 2016; Lobo et al., 2017). The antioxidant activity demonstrated is thought to be due to the various bioactive compounds (phenolics, tannins and flavonoids), naturally present in the cultivar (Table 4), and DPPH radical scavenging ability is mainly by electron transfers, and to a lesser extent by hydrogen donating abilities (Huang et al., 2015). The fermentation was beneficial to the release of these bioactive compounds, possibly as their complex forms were broken down into simpler forms, as reported by various authors (Chu and Chen, 2006; Jayabalan et al., 2008; Bhattacharya et al., 2013; Gamboa-Gómez et al., 2016; Bhattacharya et al., 2016). Compared to tea Kombucha (Lobo et al., 2017), the phenolic content of the sample is lower, but its flavonoid content is higher.

Table 4 also shows that the snake fruit Kombucha inhibited Staphylococcus aureus (Gram-positive bacteria) and Escherichia coli (Gramnegative bacteria), with the former being more inhibited. This indicated that natural bioactive compounds of the snake fruit possessed antibacterial acitivity, which agrees with the observations of Chusnie and Lamb (2011) and Daglia (2012), as phenolic compounds and flavonoids are referred to as potent antimicrobial agents against pathogenic bacteria. Possibly, as the bioactivity was enhanced by the fermentation, the inhibition was pronounced and enhanced by the presence of organic acids produced by acetobacteria in the Kombucha consortium. Fig. 2 shows the organic acid profile of the Salak Suwaru Kombucha, and this revealed acetic acid (retention time of $16.6 \mathrm{~min}$ ) as the major organic acid, in addition to others. The antimicrobial activity of tea Kombucha is largely attributable to the presence of organic acids, particularly

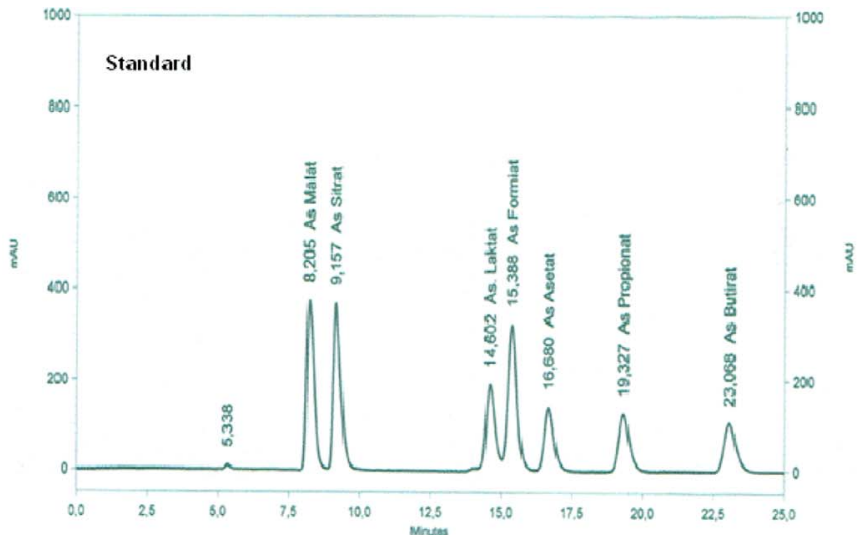

(a)

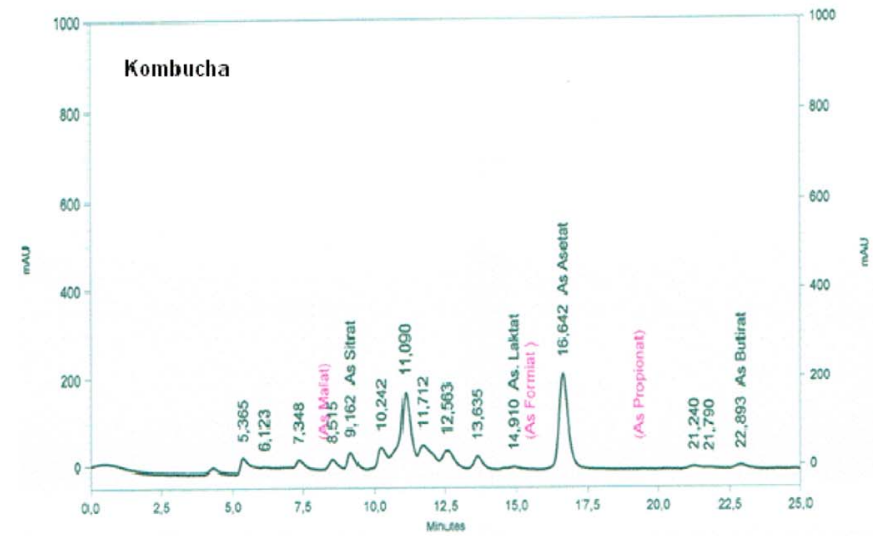

(b)

Fig. 2. HPLC chromatogram of the organic acids in the snake fruit Kombucha. (A) standard, (B) snake fruit Kombucha.

acetic acid, which can inhibit a number of Gram-positive and Gramnegative microorganisms (Sreeramulu et al, 2000; Jayabalan et al., 2014). The antimicrobial activity of weak organic acids, including acetic acid, is multifactorial and includes the ability of the undissociated acid to diffuse freely across lipid bilayers and liberate protons in the cytoplasm, lowering the cytoplasmic $\mathrm{pH}$, the intercalation of the undissociated acid into the lipid bilayers at low external $\mathrm{pH}$ and the consequences of anion accumulation. Acidification of bacteria cytoplasms may prevent growths by inhibition of glycolysis, prevention of active transport or interference with signal transductions (Lambert and Stratford, 1999; Roe et al., 2002).

\section{Conclusions}

Sugared snake fruit juices from five Indonesian snake fruit cultivars (Salak Doyong, Salak Madu, Salak Pondoh, Salak Segaran, and Salak Suwaru) can potentially be used for fermented beverages with the Kombucha consortium. The fermentation affected physicochemical and sensory properties of the juices. With a focus on the most promising cultivar, the Kombucha fermentation enhanced the antioxidant and antibacterial activities of the resulting products, so also were the bioactive compounds, with desirable overall properties of the fermented beverage. Snake fruits, therefore, have the potential for functional food development by fermentation with the Kombucha consortium.

\section{Conflict of interest}

The authors declare no conflict of interest 


\section{References}

Aloulou, A., Hamden, K., Elloumi, D., Ali, M.B., Hargafi, K., Jaouadi, B., Ayadi, F., Elfeki, A., Ammar, E., 2012. Hypoglycemic and antilipidemic properties of Kombucha tea in alloxan-induced diabetic rats. BMC Complement. Altern. Med. 12, 63-71.

Anon, 2017. WMA Declaration of Helsinki - Ethical Principles for Medical Research Involving Human Subjects. 〈https://www.wma.net/policies-post/wma-declarationof-helsinki-ethical-principles-for-medical-research-involving-human-subjects $/>$ (accessed 5 December 2017).

Aralas, S., Mohamed, M., Abu Bakar, M.F., 2009. Antioxidant properties of selected salak (Salacca zalacca) varieties in Sabah, Malaysia. Nutr. Food Sci. 39 (3), 243-250.

Ayed, L., Abid, S.B., Hamdi, M., 2017. Development of a beverage from red grape juice fermented with theKombucha consortium. Ann. Microbiol. 67, 111-121.

Banerjee, D., Hassarajani, S.A., Maity, B., Narayan, G., Bandyopadhyay, S.K., Chattopadhyay, S., 2011. Comparative healing property of kombucha tea and black tea against indomethacin-induced gastric ulceration in mice: possible mechanism of action. Food Funct. 1, 284-293.

Bhattacharya, D., Bhattacharya, S., Patra, M.M., Chakravorty, S., Sarkar, S., Chakraborty, W., Koley, H., Gachhui, R., 2016. Antibacterial activity of polyphenolic fraction of Kombucha against enteric bacterial pathogens. Curr. Microbiol. 73 (6), 885-896.

Bhattacharya, S., Gachhui, R., Sil, P.C., 2013. Effect of kombucha, a fermented black tea in attenuating oxidative stress mediated tissue damage in alloxan-induced diabetic rats. Food Chem. Toxicol. 60, 328-340.

Blanc, P.J., 1996. Characterization of the tea fungus metabolites. Biotechnol. Lett. 18 (2), 139-142.

Chakravorty, S., Bhattacharya, S., Chatzinotas, A., Chakraborty, W., Bhattacharya, D., Gachhui, R., 2016. Kombucha tea fermentation: microbial and biochemical dynamics. Int. J. Food Microbiol. 220, 63-72.

Chu, S.C., Chen, C., 2006. Effects of origins and fermentation time on the antioxidant activities of kombucha. Food Chem. 98, 502-507.

Cushnie, T.P., Lamb, A.J., 2011. Recent advances in understanding the antibacterial properties of flavonoids. Int. J. Antimicrob. Agents 38 (2), 99-107.

Daglia, M., 2012. Polyphenols as antimicrobial agents. Curr. Opin. Biotechnol. 23 (2), 174-181.

Gamboa-Gómez, C.I., González-Laredo, R.F., Gallegos-Infante, J.A., Pérez, M.M.L., Moreno-Jiménez, M.R., Flores-Rueda, A.G., Rocha-Guzmán, N.E., 2016. Antioxidant and angiotensin-converting enzyme inhibitory activity of Eucalyptus camaldulensis and Litsea glaucescens infusions fermented with Kombucha consortium. Food Technol. Biotechnol. 54 (3), 367-374.

Granato, D., Calado, V.M.D.A., Jarvis, B., 2014. Observations on the use of statistical methods in food science and technology. Food Res. Int. 55 (2014), 137-149.

Greenwalt, C.J., Steinkraus, K.H., Ledford, R.A., 2000. Kombucha, the fermented tea: microbiology, composition, and claimed health effects. J. Food Prot. 63 (7), 976-981.

Gunam, I.B.W., Wrasiati, L.P., Setioko, W., 2009. The influence of the type and amount of sugar added on the characteristics of the salak wine. Agrotekno 15 (1), 12-19.

Hatano, T., Kagawa, H., Yasuhara, T., Okuda, T., 1988. Two new flavonoids and other constituents in licorice root: their relative astringency and radical scavenging effects. Chem. Pharm. Bull. 36 (6), 2090-2097.

Huang, W., Cash, N., Wen, L., Szatmary, P., Mukherjee, R., Armstrong, J., Chvanov, M., Tepikin, A.V., Murphy, M.P., Sutton, R., Criddle, D.N., 2015. Effects of the mitochondria-targeted antioxidant mitoquinone in murine acute pancreatitis. Mediat. Inflamm. 2015 (Article ID 901780, 13 pages).

Islam, Md.K., Khan, M.Z.H., Sarkar, M.A.R., Absar, N., Sarkar, S.K., 2013. Changes in acidity, TSS, and sugar content at different storage periods of the postharvest mango (Mangifera indica L.) influenced by bavistin DF (Article ID 939385). Int. J. Food Sci. http://dx.doi.org/10.1155/2013/939385.

Jayabalan, R., Marimuthu, S., Swaminathan, K., 2007. Changes in content of organic acids and tea polyphenols during kombucha tea fermentation. Food Chem. 102, 392-398.

Jayabalan, R., Malba`sa, R.V., Lon`car, E.S., Vitas, J.S., Sathishkumar, M., 2014. A review on kombucha tea-microbiology, composition, fermentation, beneficial effects, toxicity, and tea tungus. Compr. Rev. Food Sci. Food Saf. 13, 538-550.

Jayabalan, R., Subathradevi, P., Marimuthu, S., Sathishkumar, M., Swaminathan, K., 2008. Changes in free radical scavenging ability of kombucha tea during fermentation. Food Chem. 109, 227-234.
Jayabalan, R., Malini, K., Sathishkumar, M., Swaminathan, K., Yun, S.E., 2010. Biochemical characteristics of tea fungus produced during kombucha fermentation. Food Sci. Biotechnol. 19, 843-847.

Jayabalan, R., Chen, P.N., Hsieh, Y.S., Prabhakaran, K., Pitchai, P., Marimuthu, S., Thangaraj, P., Swaminathan, K., Yun, S.E., 2011. Effect of solvent fractions of kombucha tea on viability and invasiveness of cancer cells - characterization of dimethyl 2-(2-hydroxy-2-methoxypropylidine) malonate and vitexin. Indian J. Biotechnol. 10, $75-82$.

Lambert, R.J., Stratford, M., 1999. Weak acid preservative: modelling microbial inhibition and response. J. Appl. Microbiol. 86, 157-164.

Lobanova, A.V., Strelnikov, L.S., Dolya, V.G., Strilets, O.P., 2016. Studying the Properties of the Microbial Consortium "kombucha" and Creation New Products on Their Basis. Tropical Issues of New Drugs Development Vol. 1. Ministry of Public Health of Ukraine, National University of Pharmacy, Kharkiv, Ukraine, pp. 362-363.

Lobo, R.O., Dias, F.O., Shenoy, C.K., 2017. Kombucha for healthy living: evaluation of antioxidant potential and bioactive compounds. Int. Food Res. J. 24 (2), 541-546.

Maturin, L., Peeler, J.T., 2001. Aerobic plate count. In: BAM: Bacteriological Analytical Manual (Chapter 3). U.S. Food and Drug Administration, Maryland. 〈http://www. fda.gov/Food/FoodScienceResearch/LaboratoryMethods/ucm063346.htm $\rangle$ (accessed 12 December 2017).

Mohd Zaini, N.A., Osman, A., Hamid, A.A., Ebrahimpour, A., Saari, N., 2013. Purification and characterization of membrane-bound polyphenoloxidase (mPPO) from snake fruit (Salacca zalacca (Gaertn.) Voss. Food Chem. 136, 407-414.

Nabavi, S.M., Ebrahimzadeh, M.A., Nabavi, S.F., Hamidinia, A., Bekhradnia, A.R., 2008. Determination of antioxidant activity, phenol and flavonoids content of Parrotia persica Mey. Pharmacol. Online 2, 560-567.

Price, M.L., Socoyoc, S.V., Butler, L.G., 1978. A critical evaluation of vanillin reaction as an assay for tannin in sorghum grain. J. Agric. Food Chem. 26 (5), 1214-1218.

Ranggana, S., 1977. Manual of Analysis of Fruit and Vegetable Products. McGraw Hil Publishing Co, New Delhi.

Roe, A.J., O'Byrne, C., McLaggan, D., Booth, I.R., 2002. Inhibition of Escherichia coli growth by acetic acid: a problem with methionine biosynthesis and homocysteine toxicity. Microbiology 148, 2215-2222.

Sievers, M., Lanini, C., Weber, A., Schuler-Schmid, U., Teuber, M., 1995. Microbiology and fermentation balance in a Kombucha beverage obtained from a tea fungus fermentation. Syst. Appl. Microbiol. 18, 590-594.

Sreeramulu, G., Zhu, Y., Knol, W., 2000. Kombucha fermentation and its antimicrobial activity. J. Agric. Food Chem. 48 (6), 2589-2594.

Stone, H., Sidel, J.L., 2004. Sensory Evaluation Practices. Academic Press Inc., Tragon Corporation, Redwood City.

Suica-Bunghez, I.R., Teodorescu, S., Dulama, I.D., Voinea, O.C., Simionescu, S., and Ion, R.M., 2016. Antioxidant activity and phytochemical compounds of snake fruit (Salacca zalacca). IOP Conference Series: Materials Science and Engineering 133, 012051. Doi: 〈https://dx.doi.org/10.1088/1757-899X/133/1/012051〉.

Velićanski, A.S., Cvetković, D.D., Markov, S.L., Šaponjac, V.T., Vulić, J.J., 2014 Antioxidant and antibacterial activity of the beverage obtained by fermentation of sweetened lemon balm (Melissa officinalis L.) tea with symbiotic consortium of bacteria and yeasts. Food Technol. Biotechnol. 52 (4), 420-429.

Wolf, C.E., Gibbon, W.R., 1996. Improved method for the determination of nisin. J. Appl. Bacteriol. 80 (4), 453-457.

Yang, J., Paulino, R., Janke-Stedronsky, S., Abawi, F., 2007. Free radical scavenging activity and total phenol of noni (Moriada eitrifolia L.) juice and powder in processing and storage. Food Chem. 102 (1), 302-308.

Yavari, N., Assadi, M.M., Larijani, K., Moghadam, M.B., 2010. Response surface methodology for optimization of glucuronic acid production using kombucha layer on sour cherry juice. Aust. J. Basic Appl. Sci. 4 (8), 3250-3256.

Yavari, N., Assadi, M.M., Moghadam, M.B., Larijani, K., 2011. Optimizing glucuronic acid production using tea fungus on grape juice by response surface methodology. Aust. J. Basic Appl. Sci. 5, 1788-1794.

Zeleny, M., 1982. Multiple Criteria Decision Making. Mcgraw-Hill, New York.

Zubaidah, E., Putri, W.D.R., Puspitasari, T., Kalsum, U., Dianawati, D., 2017. The effectiveness of various salacca vinegars as therapeutic agent for management of hyperglycemia and dyslipidemia on diabetic rats (Article ID 8742514). Int. J. Food Sci. http://dx.doi.org/10.1155/2017/8742514. 